\title{
High Incidence of Enterotoxin D Producing Staphylococcus spp. in Brazilian Cow's Raw Milk and Its Relation with Coagulase and Thermonuclease Enzymes
}

\author{
Ana Maria Oliveira, Carlos Roberto Padovani, ${ }^{2}$ Norma Teruko Nagô Miya, \\ Anderson S. Sant'Ana, ${ }^{3}$ and José Luiz Pereira ${ }^{1}$
}

\begin{abstract}
In this study, the enterotoxigenic potential of Staphylococcus strains $(n=574)$ isolated from raw milk samples $(n=140)$ was determined for their capacity to produce staphylococcal enterotoxins. In addition, the relationship between the presence of enterotoxins, coagulase, and thermonuclease (Tnase) was assessed. The results showed that $19 \%$ of Staphylococcus was enterotoxigenic, being able to produce at least one of the staphylococcal enterotoxins (A, B, C, and D). Most of the strains were able to produce enterotoxin D $(68.8 \%)$, whereas $12.8 \%$ of the Staphylococcus strains were able to produce staphylococcal enterotoxin A. Besides, the production of more than one type of enterotoxins by the same strain was observed. Tnase was considered the best marker for enterotoxigenic potential of isolates, although some of them were negative for coagulase and Tnase but positive for enterotoxin production. Therefore, either the use of Tnase to assess Staphylococcus enterotoxigenic potential or the use of simple and easy screening tests for enterotoxin production should receive more attention when evaluating the pathogenic potential of foodborne Staphylococcus strains. Due to the association of both coagulase positive Staphylococcus and coagulase negative Staphylococcus with foodborne disease outbreaks, regulators and industries should pay more attention to enterotoxigenic Staphylococcus rather than focusing only on S. aureus or coagulase positive Staphylococcus. Finally, data found here suggest a high risk of staphylococcal intoxication with the consumption of raw milk or dairy products made from raw milk.
\end{abstract}

\section{Introduction}

$S$ TAPHYLOCOCCUS SPP. ARE widespread microorganisms that play an important role in foods as beneficial microorganisms (Irlinger, 2008; Zell et al., 2008; Coton et al., 2009) or as agents of foodborne diseases (Miwa et al., 2001; Do Carmo et al., 2002, 2003; Colombari et al., 2007; López et al., 2008). Foodborne diseases associated with enterotoxigenic Staphylococcus are caused by the consumption of foods contaminated with preformed enterotoxins (Le Loir et al., 2003). Among staphylococcal enterotoxins, type-A enterotoxin is responsible for almost $80 \%$ of outbreaks (Balaban and Rasooly, 2000).

The ability of Staphylococcus to produce coagulase is used to indicate enterotoxigenic potential of isolates, which are called coagulase positive Staphylococcus (CPS). Due to this, they have received more attention by both governments and industries when establishing regulations, microbiological specifications, or methods. Despite this, the ability of coagulase negative Staphylococcus (CNS) to produce enterotoxins (VernozyRozand et al., 1996; Udo et al., 1999; Zell et al., 2008) and their association with foodborne disease outbreaks have been reported (Do Carmo et al., 2002; Veras et al., 2008). The presence of CNS in foods is of concern, as they are commonly found in raw material (e.g., as milk) and may be used as starter cultures for production of fermented foods (Zell et al., 2008). Since analytical methodology assumes that enterotoxigenic Staphylococcus must produce coagulase (Lancette and Bennett, 2001), the presence of CNS is overlooked and, thus, implications for food safety may arise. Therefore, testing the potential of Staphylococcus strains to produce enterotoxins using easy and inexpensive methods (Robbins et al.,1974) may be a better choice so as to report on the enterotoxigenic potential of Staphylococcus strains. This study aimed at determining the enterotoxigenic potential of Staphylococcus strains isolated from

\footnotetext{
${ }^{1}$ Department of Food Science, Faculty of Food Engineering, University of Campinas, Campinas, São Paulo, Brazil.

${ }^{2}$ Department of Statistics, Institute of Biosciences, São Paulo State University, Botucatu, São Paulo, Brazil.

${ }^{3}$ Department of Food and Experimental Nutrition, Faculty of Pharmaceutical Sciences, University of São Paulo, São Paulo, Brazil.
} 
Brazilian raw milk and estimating the relationship between production of enterotoxins and coagulase and thermonuclease (Tnase) enzymes.

\section{Materials and Methods}

\section{Raw milk sampling}

Raw milk samples $(200 \mathrm{~mL})$ of nine different and randomly selected milk producers and a pool of them were collected during 10 months. These samples $(n=140)$ were sent by milk producers to a cooperative dairy plant located in the city of Campinas, State of São Paulo (Brazil), for milk and dairy production. Samples were collected under aseptic conditions, transported, and maintained at $4{ }^{\circ} \mathrm{C}$. Microbiological analysis was performed at the same day of sampling.

\section{Enumeration and identification of Staphylococcus spp.}

The enumeration and identification of Staphylococcus spp. in raw milk samples were performed as proposed by Lancette and Bennett (2001). An aliquot of samples $(10 \mathrm{~mL})$ was homogenized in $90 \mathrm{~mL}$ of $0.1 \%$ sterile peptone water. Decimal dilutions were prepared in tubes containing $9 \mathrm{~mL}$ of this diluent and inoculated onto Baird Parker agar (Oxoid, Basingstoke, United Kingdom) plates. The inoculum was spread over the surface of the agar using sterile rods. Plates were kept in an upright position until liquid was absorbed. Baird Parker agar plates were inverted and incubated at $37^{\circ} \mathrm{C}$ for $48 \mathrm{~h}$. Characteristic colonies of Staphylococcus spp. (circular, smooth or rough appearance, convex, gray-black surrounded by opaque and clear zones or not) were counted. About 5-10 colonies of each sample were picked up for confirmation. Confirmation at genera level was performed by using Gram's staining, production of catalase, coagulase, heat stable nuclease (Tnase), and anaerobic utilization of mannitol tests (Lancette and Bennett, 2001). Coagulase was performed using the tube method as described by Lancette and Bennett (2001), whereas Tnase production was assessed by the plate technique with toluidine blue-deoxyribonucleic acid agar (Lachica, 1976). Anaerobic fermentation of mannitol was used when isolates were negative for coagulase and Tnase tests to differentiate Staphylococcus spp. from Micrococcus spp. Since
Micrococcus is a strict aerobe, mannitol fermentation indicated that an isolate was within Staphylococcus genus (Schleifer, 1986). An isolate was considered within Staphylococcus genus when presented as gram-positive cocci in grape-like clusters, catalase, and mannitol fermentation positive. A $3+$ or $4+$ clot formation was considered as a positive reaction for Staphylococcus, whereas isolates presenting $1+$ and $2+$ clot types were only considered positive when Tnase test was also positive. The number of isolates that presented positive and negative results in coagulase and Tnase tests was recorded. Isolates presenting positive or negative reactions for coagulase and positive reaction for Tnase were investigated for their ability in producing enterotoxins.

\section{Enterotoxin production and detection}

For enterotoxin production, each of the Staphylococcus isolates were inoculated in brain-heart infusion (BHI) broth (Difco, Sparks, NV). Tubes were incubated overnight at $37^{\circ} \mathrm{C}$. BHI Agar plates were covered with membrane disks made from Spectra/membrane dialysis tubing, 6000-8000, $100 \mathrm{~mm}$ flat width (Thomas Scientific, Philadelphia, PA). Then, $0.5 \mathrm{~mL}$ of each isolate grown in $\mathrm{BHI}$ broth was inoculated in membranes, and the plates were incubated at $37^{\circ} \mathrm{C}$ for $24 \mathrm{~h}$. Membranes were washed twice with 1.5 and $1 \mathrm{~mL}$, respectively, of $0.02 \mathrm{M} \mathrm{NaHPO}_{4}$. Then, cultures were centrifuged and culture supernatants were used for enterotoxin detection (Robbins et al., 1974; Pereira et al., 1996).

For enterotoxin detection, the optimum-sensitivity plate (OSP) method was used (Robbins et al., 1974). Noble agar $(1.2 \%)$ prepared in $0.02 \mathrm{M}$ phosphate-buffered saline, $\mathrm{pH} 7.4$ was put in $50 \mathrm{~mm}$ diameter Petri dishes. Then, seven wells (five with $8.3 \mathrm{~mm}$ and two with $6.7 \mathrm{~mm}$ diameter) were cut in the agar. The antiserum, control enterotoxin, and samples were placed in the central, in the two smaller and in the four larger outer wells, respectively. Petri dishes were closed and stored in a humidified box at $37^{\circ} \mathrm{C}$ for $18 \mathrm{~h}$. The union of the precipitation line produced by isolate fluids with those formed by control indicated a positive reaction. To detect low-enterotoxinproducing strains, culture supernatant fluids were concentrated 10 times. A, B, C, and D Staphylococcal enterotoxins, together with their respective antiserum, were gently obtained

Table 1. Percentage of Enterotoxigenic Staphylococcus spP. in Raw Milk

\begin{tabular}{|c|c|c|c|}
\hline \multirow[b]{2}{*}{ Milk producers } & \multicolumn{2}{|c|}{ Enterotoxigenicity of Staphylococcus strains (\%) } & \multirow[b]{2}{*}{ Total number of isolates tested } \\
\hline & Positive & Negative & \\
\hline Pool & $15.2^{\mathrm{a}, \mathrm{b}, \mathrm{A}}$ & $84.8^{\mathrm{a}, \mathrm{b}, \mathrm{B}}$ & 66 \\
\hline $\mathrm{P} 2$ & $18.4^{\mathrm{a}, \mathrm{b}, \mathrm{A}}$ & $81.6^{\mathrm{b}, \mathrm{c}, \mathrm{B}}$ & 87 \\
\hline P3 & $11.1^{\mathrm{a}, \mathrm{b}, \mathrm{A}}$ & $88.9^{\mathrm{a}, \mathrm{b}, \mathrm{B}}$ & 45 \\
\hline P4 & $15.6^{\mathrm{a}, \mathrm{b}, \mathrm{A}}$ & $88.4^{\mathrm{a}, \mathrm{b}, \mathrm{B}}$ & 64 \\
\hline P5 & $3.3^{\mathrm{c}, \mathrm{A}}$ & $96.7^{\mathrm{a}, \mathrm{B}}$ & 61 \\
\hline P6 & $24.1^{\mathrm{a}, \mathrm{b}, \mathrm{A}}$ & $75.9^{\mathrm{b}, \mathrm{c}, \mathrm{B}}$ & 54 \\
\hline P7 & $29.8^{a, b, A}$ & $70.2^{\mathrm{b}, \mathrm{c}, \mathrm{B}}$ & 47 \\
\hline P8 & $14.6^{\mathrm{a}, \mathrm{b}, \mathrm{A}}$ & $85.4^{\mathrm{a}, \mathrm{b}, \mathrm{B}}$ & 48 \\
\hline P9 & $17.9^{\mathrm{a}, \mathrm{b}, \mathrm{A}}$ & $82.1^{\mathrm{a}, \mathrm{b}, \mathrm{c}, \mathrm{B}}$ & 39 \\
\hline P10 & $39.7^{\mathrm{a}, \mathrm{A}}$ & $60.3^{\mathrm{c}, \mathrm{B}}$ & 63 \\
\hline Mean & 19 & 81 & 574 \\
\hline
\end{tabular}

Values in the same line with different capital letters indicate significant difference (95\%) between enterotoxigenic and nonenterotoxigenic Staphylococcus strains for the same producer. Values in the same column with different small letters indicate significant difference (95\%) between enterotoxigenic and nonenterotoxigenic Staphylococcus strains among producers. 
Table 2. Types of Enterotoxins Produced by 109 Raw Milk Staphylococcus spp. Isolates

\begin{tabular}{|c|c|c|c|c|c|c|}
\hline \multicolumn{7}{|c|}{ Types of enterotoxins produced by Staphylococcus spp. isolated from raw cow milk (\%) } \\
\hline$A$ & $B$ & C & $D$ & $A-B$ & $A-D$ & $B-D$ \\
\hline 12.8 & 7.3 & 2.8 & 68.8 & 3.7 & ND & 4.6 \\
\hline
\end{tabular}

ND, nondetected.

from M.S. Bergdoll (Food Research Institute, University of Wisconsin-Madison). Different dishes were used for testing enterotoxin production by raw milk Staphylococcus isolates.

\section{Statistical analysis}

Goodman's test was used for contrasts among multinomial proportions at $5 \%$ significance level (Sheskin, 2000).

\section{Results and Discussion}

In Brazil, Salmonella spp. is the first agent causing foodborne diseases, whereas enterotoxigenic Staphylococcus is the second most important microorganism associated with these diseases. Staphylococcus are blamed for more than 572 outbreaks from 1999 to 2007 (ANVISA, 2008). Several outbreaks caused by these microorganisms have been reported in the literature (Do Carmo et al., 2002, 2003, Colombari et al., 2007; Veras et al., 2008), and some of them are linked to dairy products.

In this study, all samples presented presumptive Staphylococcus colonies, and counts of these microorganisms ranged around $8.9 \times 10^{3}-1.5 \times 10^{5}$ colony forming units $(\mathrm{CFU}) / \mathrm{mL}$, which may be indicative of poor hygiene during milking or in temperature control during transportation, as the milk came from healthy cows. From 140 samples, 574 Staphylococcus strains were isolated and tested for enterotoxins production. Despite the significant difference between some milk producers (from 11.1\% to 39.7\%) according to Goodman's statistical test $(p<0.05)$, it is possible to see in Table 1 that the average rate for the incidence of enterotoxigenic Staphylococcus was $19 \%(n=109)$. Although the percentage of enterotoxigenic strains cannot be considered high, it must be observed with concern by milk farmers and dairy processing plants. For milk farmers, the results found here indicate that although programs on mastitis control may be successful, more care should be taken with hygiene and temperature control between milking and milk being received at the dairy plant for processing. Counts of Staphylococcus aureus higher than $10^{6}$ $\mathrm{CFU} / \mathrm{g}$ or $\mathrm{mL}$ in foods are reported as the critical level for these microorganisms to produce enterotoxins and to cause foodborne disease outbreaks (Balaban and Rasooly, 2000; Le Loir et al., 2003). However, even low counts such as $10^{3} \mathrm{CFU} / \mathrm{g}$ reached by $S$. aureus may be enough for this microorganism to produce enough amount of enterotoxin $(1 \mathrm{ng} / \mathrm{g})$ to cause intoxication (Pereira et al., 1991). This reinforces the need of dairy processing plants working together with milk farmers so as to improve the microbiological quality of raw milk. Besides being a source of contamination by Staphylococcus in the processing environment, the presence of enterotoxins in raw milk samples may lead to the production of high-risk dairy products. This is because staphylococcal enterotoxins are highly stable to the steps used in dairy processing, mainly milk pasteurization (Modi et al., 1990; Schwabe et al., 1990).

According to Table 2, Staphylococcus spp. isolated from Brazilian raw milk samples were mainly producers of type D enterotoxin $(68.8 \%)$, with less than $10 \%$ of the strains producing two different types of enterotoxins. The percentage of isolates producing enterotoxin type A was low. Currently, more than 20 types of staphylococcal enterotoxins are known (Balaban and Rasooly, 2000; Pereira et al., 1991; Munson et al., 1998; Orwin et al., 2001; Omoe et al., 2005; Thomas et al., 2006; Ono et al., 2008). However, enterotoxin A is the most commonly staphylococcal enterotoxin associated with foodborne outbreaks, followed by enterotoxin D (Balaban and Rasooly, 2000). Data obtained here indicated that enterotoxin D may play an important role in staphylococcal food poisoning in

Table 3. Correlation Between Enterotoxin Production, Coagulase, and Thermonuclease By RAW MiLK STAPHYLOCOCCUS SPP. IsOlates

\begin{tabular}{|c|c|c|c|c|c|}
\hline Producer & $\begin{array}{c}\text { Thase }(+) \text { Coag } \\
(+)(\%)\end{array}$ & $\begin{array}{c}\text { Tnase (-) Coag } \\
(-)(\%)\end{array}$ & $\begin{array}{c}\text { Thase }(+) \text { Coag } \\
(-)(\%)\end{array}$ & $\begin{array}{c}\text { Tnase }(-) \text { Coag } \\
(+)(\%)\end{array}$ & $\begin{array}{c}\text { Number of } \\
\text { cultures tested }\end{array}$ \\
\hline Pool & $20^{\mathrm{c}, \mathrm{A}}$ & $30^{\mathrm{a}, \mathrm{A}}$ & $40^{\mathrm{b}, \mathrm{c}, \mathrm{A}}$ & $10^{\mathrm{A}}$ & 10 \\
\hline P2 & $87.5^{\mathrm{a}, \mathrm{b}, \mathrm{A}}$ & 0.0 & $12.5^{\mathrm{c}, \mathrm{B}}$ & 0.0 & 16 \\
\hline P3 & $20^{\mathrm{c}, \mathrm{B}}$ & 0.0 & $80^{\mathrm{a}, \mathrm{A}}$ & 0.0 & 05 \\
\hline P4 & 100 & 0.0 & 0.0 & 0.0 & 10 \\
\hline P5 & 100 & 0.0 & 0.0 & 0.0 & 02 \\
\hline P6 & $38.5^{\mathrm{b}, \mathrm{c}, \mathrm{A}}$ & 0.0 & $61.5^{\mathrm{a}, \mathrm{A}}$ & 0.0 & 13 \\
\hline P7 & $35.7^{\mathrm{b}, \mathrm{c}, \mathrm{A}}$ & 0.0 & $64.3^{\mathrm{a}, \mathrm{A}}$ & 0.0 & 14 \\
\hline P8 & $42.8^{\mathrm{b}, \mathrm{c}, \mathrm{A}}$ & $28.6^{\mathrm{a}, \mathrm{A}}$ & $28.6^{\mathrm{b}, \mathrm{c}, \mathrm{A}}$ & 0.0 & 07 \\
\hline P9 & $85.7^{\mathrm{a}, \mathrm{b}, \mathrm{A}}$ & 0.0 & $14.3^{\mathrm{b}, \mathrm{c}, \mathrm{B}}$ & 0.0 & 07 \\
\hline P10 & $92^{a, b, A}$ & 0.0 & $8.0^{\mathrm{c}, \mathrm{B}}$ & 0.0 & 25 \\
\hline
\end{tabular}

Values in the same line with different capital letters indicate significant difference (95\%) regarding coagulase and Tnase production by enterotoxigenic Staphylococcus strains for the same producer. Values in the same column with different small letters indicate significant difference (95\%) regarding coagulase and Tnase production by enterotoxigenic Staphylococcus strains among producers.

Tnase, thermonuclease; Coag, coagulase. 
Brazil, as this enterotoxin and type A enterotoxin have been commonly associated with outbreaks in which Staphylococcus strains have been implicated (Do Carmo et al., 2002, 2003; Veras et al., 2008). However, which type of staphylococcal enterotoxins is more associated with foodborne disease outbreak seems not to be relevant. This is because staphylococcal enterotoxins have very similar structure and function (Balaban and Rasooly, 2000) and will cause known symptoms if they are found in foods in enough amount to cause food poisoning.

OSP method has been chosen to screen staphylococcal enterotoxins, as it requires an easy sample preparation and setup, simple reagents, and has a sensitivity of $0.5 \mathrm{mg} / \mathrm{mL}(\mathrm{Su}$ and Wong, 1997). Table 3 shows the correlation between enterotoxigenic Staphylococcus strains and their ability to produce coagulase and Tnase. Pools P3, P6, and P7 presented higher percentages of isolates within Tnase $(+)$ and coagulase (-) group, whereas a significant difference between enterotoxin and enzymes production was only found in P3 $(p<0.05)$. It can be noticed that in pool and P8 milk producers, up to $30 \%$ of isolates were enterotoxigenic and even presented negative results for Tnase and coagulase tests $(p>0.05)$. Isolates from $\mathrm{P} 4, \mathrm{P} 5, \mathrm{P} 9$, and $\mathrm{P} 10$ milk producers presented the higher percentages of enterotoxin production when Tnase and coagulase were positive $(p<0.05)$. Among all milk producers, only one strain $(10 \%)$ of 10 tested in pool, presented enterotoxigenic potential and Tnase (-) and coagulase $(+)$. Staphylococcal isolates from pool and P3 milk producers yielded the lower percentages of correlation (20\%) between enterotoxin and coagulase/Tnase production $(p<0.05)$. This research found that a high percentage of enterotoxigenic Staphylococcus isolates were coagulase negative. Danielsson and Hellberg (1977) also reported that CNS isolated from food handlers produced SE. Additionally, data indicated that the Tnase test is more faithful to assess pathogenic potential of foodborne Staphylococcus. So, either the use of Tnase to assess Staphylococcus enterotoxigenic potential or the use of simple and easy screening tests for enterotoxin production such as OSP (Robbins et al., 1974) could be considered. Due to the association of both CPS and CNS with foodborne disease outbreaks, regulations and food industries should pay more attention to enterotoxigenic Staphylococcus rather than focusing only on S. aureus or CPS. Finally, data found here suggest a high risk of staphylococcal intoxication by raw milk or dairy products made from raw milk due to the enterotoxigenic potential of the strains isolated.

\section{Acknowledgments}

The authors acknowledge $\mathrm{CNPq}$ (Conselho Nacional de Desenvolvimento Científico e Tecnológico), Capes (Coordenação de Aperfeiçoamento de Pessoal de Nível Superior), and FAPESP (Fundação de Amparo à Pesquisa do Estado de São Paulo) for the financial support to this study.

\section{Disclosure Statement}

No competing financial interests exist.

\section{References}

ANVISA-Brazilian National Surveillance Agency. Epidemiological surveillance of foodborne diseases outbreaks. 2008. Available at www.anvisa.gov.br, accessed January 10, 2009.
Balaban $\mathrm{N}$ and Rasooly A. Staphylococcal enterotoxins. Int J Food Microbiol 2000;61:1-10.

Colombari V, Mayer MDB, Laicini ZM, et al. Foodborne outbreak caused by Staphylococcus aureus: phenotypic and genotypic characterization of strains of food and human sources. J Food Prot 2007;70:489-493.

Coton E, Desmonts M-H, Leroy S, et al. Biodiversity of coagulase-negative staphylococci in French cheeses, dry fermented sausages, processing environments and clinical samples. Int J Food Microbiol 2009;137:221-229.

Danielsson ML and Hellberg B. The biochemical activity of enterotoxin and non-enterotoxin producing staphylococci. Acta Vet Scand 1977;18:266-73.

Do Carmo LS, Dias RS, Linardi VR, et al. Food poisoning due to enterotoxigenic strains of Staphylococcus present in minas cheese and raw milk in Brazil. Food Microbiol 2002;19:9-14.

Do Carmo LS, Souza Dias R, Linardi VR, et al. An outbreak of staphylococcal food poisoning in the municipality of Passos, MG, Brazil. Braz Arch Biol Technol 2003;46:581-586.

Irlinger F. Safety assessment of dairy microorganisms: coagulasenegative staphylococci. Int J Food Microbiol 2008;126:302-310.

Lachica R. Simplified thermonuclease test for rapid identification of Staphylococcus aureus recovered on agar media. Appl Environ Microbiol 1976;32:633-634.

Lancette GA and Bennett RW. Staphylococcus aureus and Staphylococcal enterotoxins. In: Compendium of Methods for the Microbiological Examination of Foods. $4^{\text {th }}$ edition. Downes FP and Ito K (eds.). Washington, DC: American Public Health Association, 2001, pp. 387-400.

Le Loir Y, Baron F, and Gautier M. Staphylococcus aureus and food poisoning. Genet Mol Res 2003;2:63-76.

López C, Feltri A, Leotta G, et al. Foodborne disease outbreak in el huecú community, province of Neuquén. Rev Argent Microbiol 2008;40:198-203.

Miwa N, Kawamura A, Masuda T, et al. An outbreak of food poisoning due to egg yolk reaction-negative Staphylococcus aureus. Int J Food Microbiol 2001;64:361-366.

Modi NK, Rose SA, and Tranter HS. The effects of irradiation and temperature on the immunological activity of staphylococcal enterotoxin A. Int J Food Microbiol 1990;11:85-92.

Munson SH, Tremaine MT, Betley MJ, et al. Identification and characterization of staphylococcal enterotoxin types G and I from Staphylococcus aureus. Infect Immun 1998;66:3337-3348.

Omoe K, Imanishi K, Hu D-L, et al. Characterization of novel staphylococcal enterotoxin-like toxin type P. Infect Immun 2005;73:5540-5546.

Ono HK, Omoe K, Imanishi $\mathrm{K}$, et al. Identification and characterization of two novel staphylococcal enterotoxins, types $\mathrm{S}$ and T. Infect Immun 2008;76:4999-5005.

Orwin PM, Leung DYM, Donahue HL, et al. Biochemical and biological properties of staphylococcal enterotoxin K. Infect Immun 2001;69:360-366.

Pereira JL, Salzberg SP, and Bergdoll MS. Production of staphylococcal enterotoxin D in foods by low-enterotoxinproducing staphylococci. Int J Food Microbiol 1991;14:19-25.

Pereira ML, Do Carmo LS, Dos Santos EJ, et al. Enterotoxin H in staphylococcal food poisoning. J Food Prot 1996;59:559-561.

Robbins R, Gould S, and Bergdoll M. Detecting the enterotoxigenicity of Staphylococcus aureus strains. J Appl Microbiol 1974;28:946-950.

Schleifer KH. Micrococcaceae. In: Bergey's Manual of Systematic Bacteriology. Volume 2. Sneath PHA, Mair NS, Sharpe ME, and Holt JG. (eds.). Baltimore: Williams and Wilkins, 1986, pp. 1003-1035. 
Schwabe M, Notermans S, Boot R, et al. Inactivation of staphylococcal enterotoxins by heat and reactivation by high $\mathrm{pH}$ treatment. Int J Food Microbiol 1990;10:33-42.

Sheskin DJ. Handbook of Parametric and Nonparametric Statistical Procedures. $3^{\text {rd }}$ edition. Boca Ratón, FL: Chapman and Hall/CRC, 2000.

Su Y-C and Wong ACL. Current perspectives on detection of staphylococcal enterotoxins. J Food Prot 1997;60:195-202.

Thomas DY, Jarraud S, Lemercier B, et al. Staphylococcal enterotoxin-like toxins $\mathrm{U} 2$ and $\mathrm{V}$, two new staphylococcal superantigens arising from recombination within the enterotoxin gene cluster. Infect Immun 2006;74:4724-4734.

Udo EE, Al-Bustan MA, Jacob LE, et al. Enterotoxin production by coagulase-negative staphylococci in restaurant workers from Kuwait city may be a potential cause of food poisoning. J Med Microbiol 1999;48:819-823.

Veras JF, Do Carmo LS, Tong LC, et al. A study of the enterotoxigenicity of coagulase-negative and coagulase-positive staphylococcal isolates from food poisoning outbreaks in Minas Gerais, Brazil. Int J Infect Dis 2008;12:410-415.
Vernozy-Rozand C, Mazuy C, Prevost G, et al. Enterotoxin production by coagulase-negative staphylococci isolated from goats' milk and cheese. Int J Food Microbiol 1996;30:271-280.

Zell C, Resch M, Rosenstein R, et al. Characterization of toxin production of coagulase-negative staphylococci isolated from food and starter cultures. Int J Food Microbiol, 2008;127: 246-251.

Address correspondence to: José Luiz Pereira, Ph.D.

Deparment of Food Science Faculty of Food Engineering University of Campinas Rua Monteiro Lobato 80

Caixa Postal 6121 Campinas, SP 13081-970

Brazil

E-mail: pereira@fea.unicamp.br 
